\title{
TERT promoter hotspot mutations are recurrent in myxoid liposarcomas but rare in other soft tissue sarcoma entities
}

Christian Koelsche ${ }^{1,2+}$, Marcus Renner ${ }^{3 \dagger}$, Wolfgang Hartmann ${ }^{4}$, Regine Brandt ${ }^{3}$, Burkhard Lehner ${ }^{5}$, Nina Waldburger ${ }^{3}$, Ingo Alldinger ${ }^{6}$, Thomas Schmitt ${ }^{7}$, Gerlinde Egerer ${ }^{7}$, Roland Penzel ${ }^{3}$, Eva Wardelmann ${ }^{4}$, Peter Schirmacher ${ }^{3}$, Andreas von Deimling ${ }^{1,2}$ and Gunhild Mechtersheimer ${ }^{3^{*}}$

\begin{abstract}
Background: Recently, recurrent point mutations in the telomerase reverse transcriptase (TERT) promoter region have been found in many human cancers, leading to a new transcription factor binding site, increased induction of TERT and subsequently to telomere maintenance. We determined the prevalence of TERT promoter mutations in soft tissue sarcomas of 341 patients comprising 16 entities and in 16 sarcoma cell lines covering 7 different soft tissue sarcoma types.
\end{abstract}

Methods: The sarcoma tissue samples were collected from the archives of the Institute of Pathology, University of Heidelberg and were composed of 39 myxoid liposarcomas (MLS), 61 dedifferentiated liposarcomas, 15 pleomorphic liposarcomas, 27 leiomyosarcomas, 25 synovial sarcomas (SS), 35 malignant peripheral nerve sheath tumors (MPNST), 40 undifferentiated pleomorphic sarcomas, 17 myxofibrosarcomas, 9 low grade fibromyxoid sarcomas, 10 cases of dermatofibrosarcoma protuberans, 31 solitary fibrous tumors (SFT), 8 extraskeletal myxoid chondrosarcomas, 9 angiosarcomas, 6 alveolar soft part sarcomas, 5 clear cell sarcomas and 4 epithelioid sarcomas. Sarcoma cell lines were obtained from the raising laboratories. A 193 bp fragment of the TERT promoter region covering the hot-spot mutations C228T and C250T was amplified, and direct sequencing of the PCR products was performed.

Results: TERT promoter mutations were detected in 36/341 sarcomas. They were highly recurrent in MLS (29/39; 74\%) and were in the present MLS series not associated with the phenotype (myxoid vs. round cell variant), tumor grade, tumor site and patients' median age or gender. In the remaining cases, TERT promoter mutations were found only in $7 / 302$ sarcoma samples and confined to SFTs $(4 / 31 ; 13 \%)$, MPNSTs $(2 / 35 ; 6 \%)$, and SSs $(1 / 25 ; 4 \%)$. Within the collection of sarcoma cell lines examined, TERT promoter mutations were detected in two MLS and in one of three MPNST cell lines.

Conclusions: TERT promoter mutations are frequent in MLSs including their round cell variants, representing the most prevalent mutation identified in this sarcoma entity to date, and in a minor fraction of SFTs, MPNSTs and SSs. The majority of sarcomas are devoid of TERT promoter hotspot mutations. These data suggest that telomere maintenance through increased expression of telomerase plays an important role in the pathogenesis especially of MLS.

Keywords: TERT, Promoter, Mutation, Soft tissue, Sarcoma, Myxoid liposarcoma, Solitary fibrous tumor

\footnotetext{
* Correspondence: gunhild.mechtersheimer@med.uni-heidelberg.de

${ }^{\dagger}$ Equal contributors

${ }^{3}$ Department of General Pathology, Institute of Pathology, University Hospital, Im Neuenheimer Feld 224, Heidelberg D-69120, Germany

Full list of author information is available at the end of the article
} 


\section{Background}

Soft tissue sarcomas (STS) are a highly heterogeneous group of malignant tumors of mesenchymal origin represented by voluntary muscles, fat, and fibrous tissue and their vessels and by convention the peripheral nervous system [1]. STS are relatively rare and constitute approximately $1-2 \%$ of all human cancers, but incidence dramatically increases with age [1,2].

Since most patients with STS present with a painless swelling, a delayed diagnosis is common, often with local or distant metastatic spread at the time of diagnosis [2]. The treatment of choice depends on the individual tumor type, grading and staging status. Surgery, among others, is a key element of therapy in sarcomas of adults with the aim of microscopically tumor-negative margins for optimal local control [3]. However, standardized treatment might be insufficient. Under these circumstances, advance in personalized treatment strategies might become important with the goal to individual tumor-targeted therapies.

That is why the biology of STS has intensively been investigated over the last decades with a dramatic increase of knowledge about genetic alterations [4] including aberrant DNA methylation [5]. In general, sarcomas can be classified into two genetic groups: i. sarcomas with specific chromosomal rearrangements on a background of relatively few other chromosomal changes, and ii. sarcomas without specific alterations on a complex background of numerous chromosomal changes [6]. Specific genetic alterations are not only of diagnostic significance, but also might become relevant for tumor-targeted therapies.

Telomere maintenance is an important step during tumorigenesis and confers unlimited proliferative capacity to cancer cells [7]. In principal, two mechanisms can be involved in telomere maintenance: a telomerase dependent mechanism or a non-telomerase dependent mechanism also referred to as Alternative Lengthening of Telomeres (ALT) [7]. The ribonucleoprotein complex telomerase provides the physiological mechanism that maintains telomere length by adding repetitive hexanucleotide repeats with the sequence $5^{\prime}$-TTAGGG-3' to telomeres. Reactivation of telomerase has been observed in the majority of human cancers [8]. In this context, telomerase reverse transcriptase (TERT) serves as the catalytic subunit of the telomerase complex and has been shown to contribute to the immortalization of cancer cells [7]. However, the underlying mechanism of TERT reactivation in cancer cells was an unresolved issue [9].

Recently, highly recurrent somatic mutations in the promoter region of the TERT gene have been detected [10]. The most frequent mutations were a single cytosine exchange to thymine at chromosome 5 base position
$1,295,228(\mathrm{C} 228 \mathrm{~T})$ or less frequently at base position 1,295,250 (C250T) ( -124 and -146 bp from ATG start site, respectively). These TERT mutations lead to a new binding motif for E-twenty six/ternary complex factors (Ets/TCF) transcription factors and results in an up to 4-fold increase of TERT promoter activity in reporter gene assays $[11,12]$.

First described in melanomas [11,12], TERT promoter mutations have subsequently been found in many other human cancer types, with highest frequencies in subtypes of CNS tumors, in a number of malignancies of epithelial origin including bladder carcinomas, thyroid carcinomas, and hepatocellular carcinomas, and in atypical fibroxanthomas and in dermal pleomorphic sarcomas [13-26]. Accordingly, TERT promoter mutations belong to the most common somatic genetic lesions in human cancers.

A study by Killela et al. investigated a broad range of human cancers for TERT promoter mutations, including soft tissue sarcomas [16]. However, the case number of single STS entities was limited and a number of subtypes were not comprised.

Therefore, the present study was conducted to investigate the prevalence of TERT promoter mutations in a comprehensive series of 341 soft tissue tumors comprised of 16 types including rare entities and in 16 cell lines of seven sarcoma types. Further, we looked for associations, if any, with clinicopathological parameters.

\section{Materials and methods}

\section{Sarcoma samples and clinicopathological characteristics}

The sarcoma tissue samples were collected at the Institute of Pathology, University of Heidelberg, and diagnoses were confirmed by three sarcoma pathologists (GM, WH and EW). Diagnoses were based on standard histopathological criteria in conjunction with immunohistological and molecular analysis according to the current WHO classification of tumors [1]. Only samples with at least $80 \%$ vital tumor cells were selected for the analysis. The study was approved by the ethics committee, medical faculty of heidelberg University (No. 206/2005, 207/2005). The clinicopathological characteristics are shown in Additional file 1: Table S1. Further molecular and histological data of myxoid liposarcomas are given in Additional file 1: Table S2. The sarcoma cell lines examined, together with references, molecular confirmation and culture conditions are detailed in Additional file 1: Table S3 (according to reference [5]).

\section{DNA isolation}

DNA was extracted from 1 to 3 (depending on the size of the tumor sample) $8 \mu \mathrm{m}$ thick sections from formalin-fixed and paraffin embedded (FFPE) samples using the Maxwell $^{\circ} 16$ FFPE Tissue LEV DNA Purification 
Kit (Promega, Madison, USA) according to the manufacturer's instructions. The extracted DNA was quantified with the Nanodrop ND-1000 spectrophotometer (NanoDrop Technologies, Rockland, USA).

\section{Direct (Sanger) sequencing}

A 193 bp fragment of the TERT promoter region spanning the hotspot mutations at positions 1,295,228 and $1,295,250$ on chromosome 5 was amplified by using GoTaq G2 Hot Start Polymerase (Promega, Madison, USA) and the following primers: hTERT-seq-for $5^{\prime}$ CACCCGTCCTGCCCCTTCACCTT-3' and hTERT-seqrev 5' - GGCTTCCCACGTGCGCAGCAGGA-3'. PCR was performed with $100 \mathrm{ng}$ of DNA template in a total volume of $25 \mu \mathrm{l}$, and included initial denaturation at $95^{\circ} \mathrm{C}$ for $120 \mathrm{~s}$, followed by 35 cycles with denaturation at $95^{\circ} \mathrm{C}$ for $30 \mathrm{~s}$, annealing at $68^{\circ} \mathrm{C}$ for $30 \mathrm{~s}$, and extension at $72^{\circ} \mathrm{C}$ for $40 \mathrm{~s}$. In cases where amplification of the large fragment failed, primers hTERT-short-for 5'-CAGCGC TGCCTGAAACTC-3' and hTERT-short-rev, 5'-GTC CTGCCCCTTCACCTT-3', which amplify a 163 bp fragment, were applied as described previously [17]. PCR products were purified using USB Exo-SAP-IT (Affymetrix, Cleveland, USA) and direct sequencing of the PCR products was performed for both strands on an ABI 3500 genetic analyzer (Life Technologies, Darmstadt, Germany) using a version 1.1 BigDye Terminator cycle sequencing kit and a BigDye Xterminator purification kit (Life Technologies, Foster City, USA).

\section{Statistical analysis}

Fisher's exact test was used to examine associations between nominal variables. Student's $t$ test was used to examine the association between nominal variables and age. Significance was defined as $\mathrm{p}<0.05$.

\section{Results}

TERT promoter hotspot mutations in soft tissue sarcomas TERT promoter mutations were detected in 36 of 341 sarcoma samples from 341 patients (10.5\%; Table 1). The mutations comprised $32 \mathrm{C} 228 \mathrm{~T}$ mutations, but only three C250T mutations. They occurred in a mutual exclusive manner with a heterozygous genotype (Figure 1). Mutations were highly recurrent $(29 / 39 ; 74 \%)$ in myxoid liposarcomas (MLS) and were almost exclusively found at position $\mathrm{C} 228 \mathrm{~T}$ with the exception for one case with a C250T mutation. Remarkably, the 28 MLS carrying a C228T mutation were all positive for the FUS-DDIT3 fusion, while the C250T mutation was found in one of two MLS with an EWSR1-DDIT3 fusion transcript (Additional file 1: Table S2). Looking for associations between the TERT promoter mutation status and clinicopathological features of the MLS (Table 2), there were no associations between TERT promoter mutational status and phenotype (myxoid vs. round cell variant), tumor grading, tumor site and patients' median age or gender. Solitary fibrous tumors (SFTs) showed TERT promoter mutations in four cases $(4 / 31 ; 13 \%)$, which were exclusively located at position C228T. In addition, two malignant peripheral nerve sheath tumors (MPNSTs) harbored a TERT promoter mutation $(2 / 35 ; 6 \%)$, one case with a $\mathrm{C} 228 \mathrm{~T}$ and the other one with a C250T mutation. Finally, a TERT promoter mutation at position C228T was found in one of the synovial sarcomas (SSs) examined $(1 / 25 ; 4 \%)$. All other sarcoma types, which comprised 61 dedifferentiated liposarcomas, 15 pleomorphic liposarcomas, 27 leiomyosarcomas, 40 undifferentiated pleomorphic sarcomas, 17 myxofibrosarcomas, 9 low-grade fibromyxoid sarcomas, 10 dermatofibrosarcomata protuberans, 8 extraskeletal myxoid chondrosarcomas, 9 angiosarcomas, 6 alveolar soft part sarcomas, 5 clear cell sarcomas, and 4 epithelioid sarcomas had a wild type genotype at the two TERT promoter hotspot loci (Table 1).

\section{TERT promoter hotspot mutations in soft tissue sarcoma cell lines}

We also sequenced 16 sarcoma cell lines for the TERT promoter hotspot mutations (Table 3). Mutations were found in both MLS cell lines and in one of three MPNST cell lines. Mutations were restricted to the C228T locus. The genotype at the two hotspot positions of the TERT promoter of the remaining cell lines, which included two well-differentiated liposarcomas, one dedifferentiated liposarcomas, one pleomorphic liposarcoma, one liposarcoma not further subtyped, four SSs, and one fibrosarcoma, was wild type.

\section{Discussion}

Telomere maintenance mechanisms represent a pivotal cornerstone in the development and sustainment of cancer. The recently described mutations in the promoter region of TERT provide new evidence for the important role of telomerase reactivation in human cancers. The overall prevalence of TERT promoter hotspot mutations was low in the comprehensive series of soft tissue sarcomas examined in this study $(36 / 341 ; 10.5 \%)$. However, the prevalence strongly varied by sarcoma type.

The by far highest mutation rate was found in MLS (29/39; 74\%), which represents the most prevalent mutation identified in this sarcoma entity to date, and which corroborates data obtained in a recent study on a smaller series of MLS [16]. In MLS, increased TERT transcription [27-29] and telomerase reactivity [28] have been described previously. Costa et al. found telomerase reactivation in $69 \%$ of MLS with an additional round cell component (high grade) [28], which is overlapping with the overall TERT promoter mutation frequency of $74 \%$ (29/39) in our series of MLS. However, in pure MLS 
Table 1 Prevalence of TERT promoter hotspot mutations in soft tissue tumors

\begin{tabular}{|c|c|c|c|c|c|}
\hline Diagnosis & Mut (n) & Total (n) & Mut (\%) & $\mathrm{C} 228 \mathrm{~T}(\mathrm{n})$ & C250T (n) \\
\hline Myxoid liposarcoma & 29 & 39 & $74 \%$ & 28 & 1 \\
\hline Dedifferentiated liposarcoma & 0 & 61 & & & \\
\hline Pleomorphic liposarcoma & 0 & 15 & & & \\
\hline Leiomyosarcoma & 0 & 27 & & & \\
\hline Synovial sarcoma & 1 & 25 & $4 \%$ & & 1 \\
\hline Malignant peripheral nerve sheath tumor & 2 & 35 & $6 \%$ & 1 & 1 \\
\hline Undifferentiated pleomorphic sarcoma & 0 & 40 & & & \\
\hline Myxofibrosarcoma & 0 & 17 & & & \\
\hline Low grade fibromyxoid sarcoma & 0 & 9 & & & \\
\hline Dermatofibrosarcoma protuberans & 0 & 10 & & & \\
\hline Solitary fibrous tumor & 4 & 31 & $13 \%$ & 4 & \\
\hline Extraskeletal myxoid chondrosarcoma & 0 & 8 & & & \\
\hline Angiosarcoma & 0 & 9 & & & \\
\hline Alveolar soft part tumor & 0 & 6 & & & \\
\hline Clear cell sarcoma & 0 & 5 & & & \\
\hline \multirow[t]{2}{*}{ Epithelioid sarcoma } & 0 & 4 & & & \\
\hline & 36 & 341 & & 33 & 3 \\
\hline
\end{tabular}

without the round cell phenotype (corresponding to low grade), they found telomerase reactivation only in $39 \%$ of cases [28]. Likewise, Schneider-Stock et al. detected telomerase activity in 30\% of MLS, but elevated TERT mRNA levels in a much higher proportion of cases $[27,29,30]$. Furthermore, intratumoral heterogeneity of TERT expression and telomerase activity has been observed in sarcomas, in particular in liposarcomas [31]. Thus, TERT mRNA levels are not stringently correlated with telomerase enzyme activity. This might be explained by sufficient regulatory mechanisms of the enzymatic function of telomerase, which still have to be functional in some tumors.

Indeed, regulatory mechanisms of telomerase have already been described at the transcriptional and posttranslational level. At the transcriptional level, alternative splicing of TERT mRNA itself might not only lead to TERT variants with impaired catalytic functions [32], but also to a variant that acts in a dominant-negative manner on telomerase activity [33]. Furthermore, post-translational

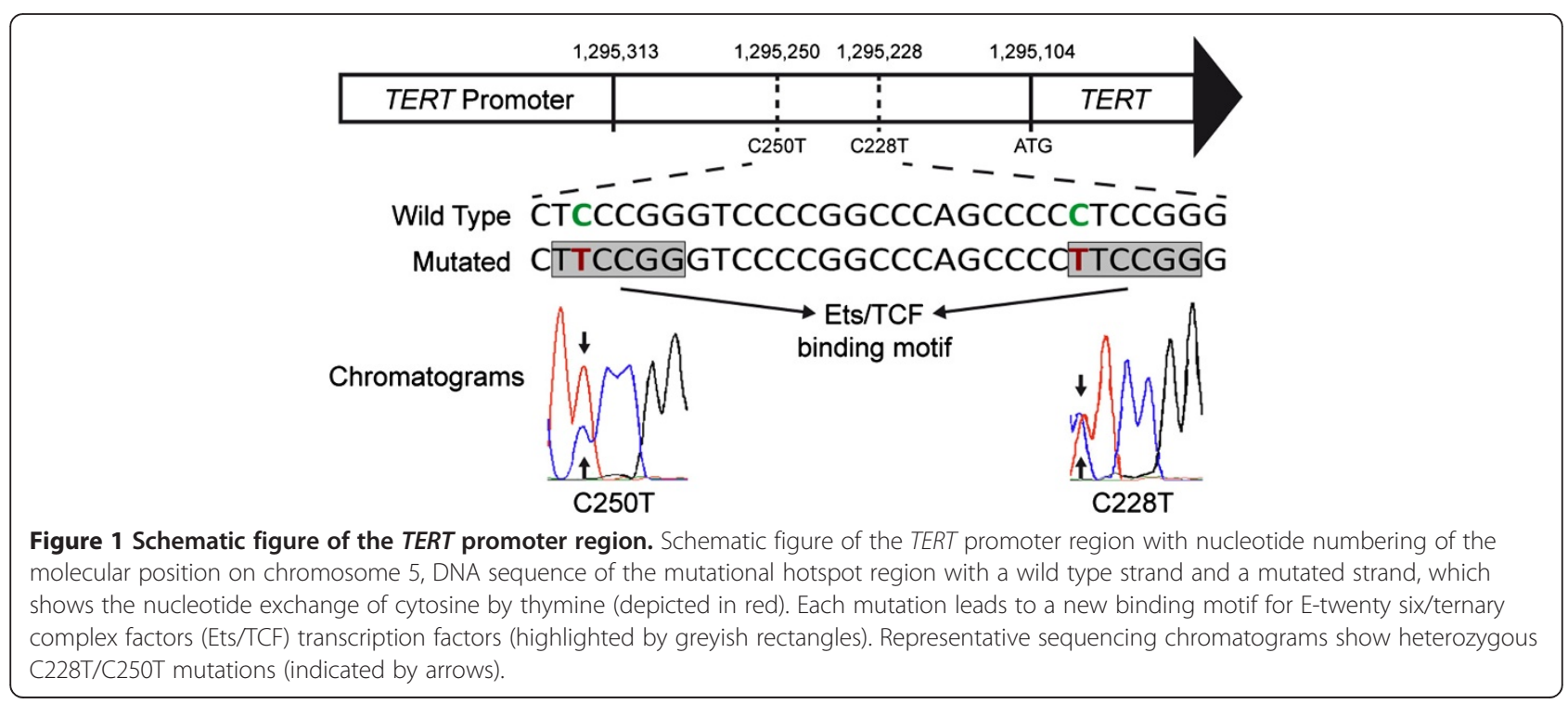


Table 2 Correlation between clinicopathological patient characteristics and TERT promoter genotype in myxoid liposarcomas

\begin{tabular}{|c|c|c|c|}
\hline & Mutant & Wild-type & $P$ value \\
\hline Phenotype $(n=39)$ & & & 0.2125 \\
\hline Myxoid & 23 & 6 & \\
\hline Round cell & 6 & 4 & \\
\hline Grading $(n=39)$ & & & 0.6034 \\
\hline G1 & 3 & 1 & \\
\hline G2 & 22 & 6 & \\
\hline G3 & 4 & 3 & \\
\hline Localization ( $n=39$ ) & & & 0.1958 \\
\hline Extremity & 23 & 10 & \\
\hline Other & 5 & 0 & \\
\hline Age (years) $(n=39)$ & & & 0.6748 \\
\hline Mean $\pm S D$ & $48 \pm 3$ & $50 \pm 5$ & \\
\hline Median (range) & $46(16-84)$ & $43(36-74)$ & \\
\hline Gender ( $n=39)$ & & & 0.6395 \\
\hline Female & 9 & 3 & \\
\hline Male & 20 & 7 & \\
\hline
\end{tabular}

Table 3 List of soft tissue sarcoma cell lines with the corresponding TERT promoter mutation status

\begin{tabular}{lll}
\hline Cell line name & Origin & TERT promoter \\
\hline T449 & WDLS & WT \\
T778 & WDLS & WT \\
FU-DDLS-1 & DDLS & WT \\
MLS402 & MLS & C228T \\
MLS1765 & MLS & C228T \\
LiSa-2 & PLS & WT \\
SW872 & LS & WT \\
1273 & SS & WT \\
HS-SY-II & SS & WT \\
SYO-1 & SS & WT \\
Fuji & SS & WT \\
CME & SS & WT \\
STS26T & MPNST & C228T \\
ST88-14 & MPNST & WT \\
T265 & MPNST & WT \\
HT1080 & FS & WT \\
\hline
\end{tabular}

Abbreviations: WDLS well differentiated liposarcoma, DDLS dedifferentiated liposarcoma, MLS myxoid liposarcoma, SS synovial sarcoma, MPNST malignant peripheral nerve sheath tumor, FS fibrosarcoma, LS liposarcoma, WT wild type, C228T cytosine exchange to thymine at chromosome 5 base position $1,295,228$. modifications of the TERT protein through phosphorylation or ubiquitination have been shown to affect the catalytic activity and stability of TERT [34].

Anyhow, our data suggest that mutation of the TERT promoter causes telomerase reactivation in MLS and thereby most probably provides unlimited proliferative potential. This assumption is also underpinned by a reporter gene assay of the two most common mutation variants within the promoter region of TERT, namely $\mathrm{C} 228 \mathrm{~T}$ and C250T, which were shown to lead to an augmented expression of TERT [12]. Further, the high prevalence of TERT promoter mutations not only in MLS round cell variants but also in MLS with a pure myxoid phenotype, and this irrespective of tumor grading, implies that these mutations act rather as driver than passenger mutations.

TERT promoter mutations might also have a diagnostic impact in myxoid sarcomas. Mutations were found neither in dedifferentiated liposarcomasa (DDLS), nor in pleomorphic liposarcomas (PLS), which presented myxoid areas in many cases, and were also not detectable in our series of myxofibrosarcomas, extraskeletal myxoid chondrosarcomas, dermatofibrosarcomata protuberans, and low-grade fibromyxoid sarcomas.

The absence of TERT promoter hotspot mutations in our series of DDLS and PLS is in line with previous studies, which largely observed deficient telomerase activity in high-grade liposarcomas. Instead, high-grade liposarcomas often use the ALT mechanism [28,35,36]. ALT overcomes telomere attrition through homologous recombination of telomeric DNA and characteristically presents with a pattern of telomere lengths that range from very short to abnormally long. This telomere pattern is clearly different compared to tumors with telomerase reactivation, where telomere length is found almost equal [36].It has been shown that ALT-positive liposarcomas have a notably worse outcome, and may imply a more favorable prognosis for TERT promoter mutated liposarcomas [28,37,38]. However, differences in patients outcome might be dedicated to the fact that telomere maintenance via ALT is more often applied by tumors with complex karyotypes or with a higher level of genomic instability $[39,40]$, whereas sarcomas characterized by type specific translocations rather use telomerase reactivation for telomere maintenance $[39,41]$. According to our data, this concept holds true for the group of liposarcomas. MLS are characterized by a translocation that fuses the DDIT3 (CHOP) gene on chromosome 12q13 with the FUS (TLS) gene on chromosome $16 \mathrm{p} 11$ in approximately $90 \%$ of cases, or the DDIT3 $(C H O P)$ with the EWSR1 on chromosome 22q12 in the remaining cases [42]. By contrast, DDLS typically have complex karyotypic aberrations with amplification of the chromosome 12 subregion q13-15, which includes the 
murine double minutes (MDM2) and cyclin dependent kinase-4 (CDK4) genes among others [43,44]. PLS are characterized by highly complex karyotypes [45]. The highest prevalence of ALT has been observed in DDLS and PLS, which typically have an aggressive biological behavior [28,37]. However, TERT promoter mutated MLS may undergo malignant progression to the round cell variant and then present with a similar biological behavior like ALT-positive PLS [46]. Another fact that challenges this concept is that patients suffering from ALT-positive glioblastoma have a more favorable clinical course compared to ALT-negative counterparts $[47,48]$. Thus, the unfavorable prognosis in ALT-positive liposarcomas is probably derived from the mutational signature in these tumors rather than dependent on the mechanism of telomere maintenance, and thus may considerably differ between different tumor entities.

The second most common rate of TERT promoter mutations was observed in SFT with a frequency of $13 \%$, which is concordant to data on a smaller series of SFTs [16]. However, TERT promoter mutation might be dependent on the anatomic site of presentation, since cranial SFTs and hemangiopericytomas, which are now considered to belong to the SFT family from a genetic perspective [49], have a slightly higher mutation frequency $(11 / 43 ; 26 \%)$ [17].

In MPNSTs, TERT promoter mutations were found in a small fraction of tumors $(2 / 35 ; 6 \%)$, which is slightly below the mutation frequency previously reported $(2 / 12$; 17\%) [17]. These data might suggest a minor significance in this tumor entity. On the other hand, one out of three MPNST cell lines was revealed with a TERT promoter mutation, which supports the assumption that telomerase reactivation by TERT promoter mutations might contribute to immortalization of at least a small proportion of MPNSTs. Interestingly, a previous study that focused on telomerase activity in MPNSTs found telomerase reactivation in 14 of $23(61 \%)$ MPNSTs [50]. Compared with histological grade, telomerase activity was completely restricted to high grade MPNSTs $(14 / 17 ; 82 \%)$ in that study. Indeed, the two MPNSTs with TERT promoter mutation described here presented with typical histological features of high-grade MPNSTs [51]. Moreover, in another study on 57 MPNST samples telomerase activity proved to be significantly associated with disease-specific mortality during 5 years of follow-up [52].

Another notable observation is the sporadic occurrence of TERT promoter mutations in SSs. This tumor typically applies telomerase reactivation for telomere maintenance [53], which is in concordance with our own observations (data not shown). However, like in MPNSTs, TERT promoter hotspot mutations just play a minor role in SSs with merely a single mutated case in our series $(1 / 25 ; 4 \%)$. Thus, the low mutation frequencies in MPNSTs and SSs suggest that a so far unknown mechanism beside the TERT promoter hotspot mutations may exist that provides telomerase reactivation.

Explanations for telomerase maintenance get complicated by the observation that a considerable fraction of STS do neither apply telomerase activation nor the ALT mechanism that is so far known, or even may be equipped with both mechanisms [7,36]. Further studies concerning molecular alterations in STS will in particular draw more attention to the non-coding genomic regions and hopefully elucidate the remaining unanswered questions, which mechanisms these tumors exploit to prevent telomere attrition.

\section{Conclusion}

We determined the prevalence of TERT promoter hotspot mutations in STS. Despite the overall low prevalence in this tumor group, TERT promoter mutations revealed to be a highly recurrent event in MLS and currently represent the most prevalent mutation identified in this sarcoma entity (74\%). Forthcoming studies will be needed to determine whether the TERT promoter mutational status could be of clinical relevance, especially in advanced MLS. Additionally, TERT promoter mutations were also found in a subset of SFTs (13\%), and in a number of MPNSTs (6\%) and SSs (4\%). Given the relative frequency of telomerase activation reported in MPNSTs and in SSs, the low TERT promoter mutation rate in these sarcoma types implies that a so far unknown mechanism, different from the presently known TERT promoter hotspot mutations, provides telomerase reactivation in these sarcoma entities.

\section{Additional file}

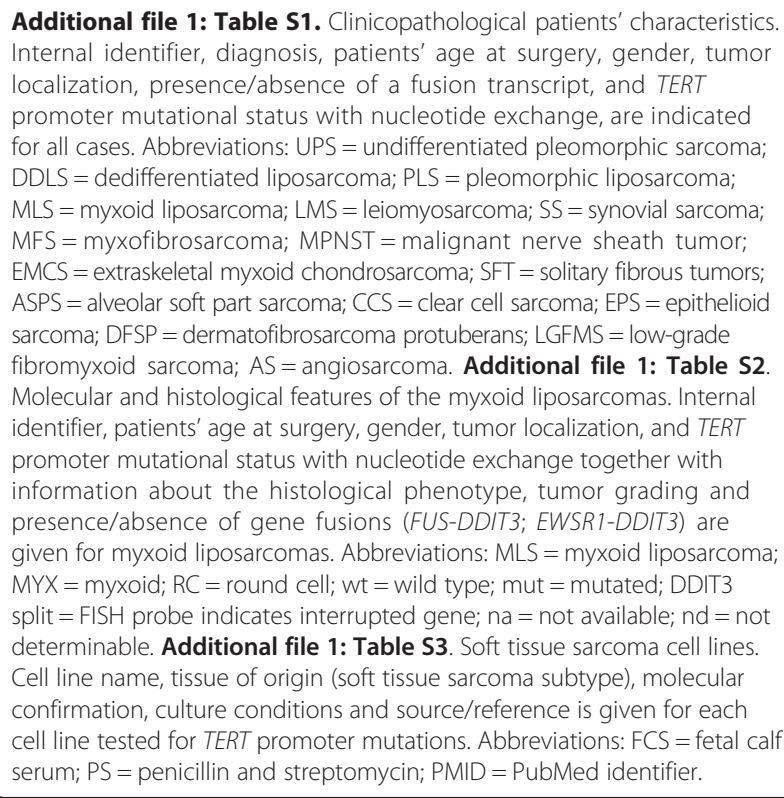

Additional file 1: Table S1. Clinicopathological patients' characteristics. Internal identifier, diagnosis, patients' age at surgery, gender, tumor localization, presence/absence of a fusion transcript, and TERT promoter mutational status with nucleotide exchange, are indicated for all cases. Abbreviations: UPS = undifferentiated pleomorphic sarcoma; DDLS = dedifferentiated liposarcoma; PLS = pleomorphic liposarcoma; MLS = myxoid liposarcoma; LMS = leiomyosarcoma; SS = synovial sarcoma; MFS = myxofibrosarcoma; MPNST = malignant nerve sheath tumor; EMCS = extraskeletal myxoid chondrosarcoma; SFT = solitary fibrous tumors; ASPS = alveolar soft part sarcoma; CCS = clear cell sarcoma; EPS = epithelioid sarcoma; DFSP = dermatofibrosarcoma protuberans; LGFMS = low-grade fibromyxoid sarcoma; $A S$ = angiosarcoma. Additional file 1: Table S2. Molecular and histological features of the myxoid liposarcomas. Internal identifier, patients' age at surgery, gender, tumor localization, and TERT promoter mutational status with nucleotide exchange together with information about the histological phenotype, tumor grading and presence/absence of gene fusions (FUS-DDIT3; EWSR1-DDIT3) are given for myxoid liposarcomas. Abbreviations: MLS = myxoid liposarcoma; $\mathrm{MYX}=$ myxoid; $\mathrm{RC}=$ round cell; $\mathrm{wt}=$ = wild type; mut = mutated; DDIT3 split = FISH probe indicates interrupted gene; na = not available; $n d=$ not determinable. Additional file 1: Table S3. Soft tissue sarcoma cell lines. Cell line name, tissue of origin (soft tissue sarcoma subtype), molecular confirmation, culture conditions and source/reference is given for each cell line tested for TERT promoter mutations. Abbreviations: FCS = fetal calf serum; PS = penicillin and streptomycin; PMID = PubMed identifier. 


\section{Competing interests}

The authors declare that they have no competing interests.

\section{Authors' contributions}

CK and MR contributed equally to this work. CK, MR, WH, EW, TS, GE, PS, AvD and GM performed data analyses. WH, EW and GM carried out the histological review of cases. CK, MR, NW and RP performed molecular analyses. AU, ERK, BL, IA, PS and GM collected cases. CK and GM conceived and designed the study, and prepared the initial manuscript. GM supervised the project. All authors contributed to the final manuscript. All authors read and approved the final manuscript.

\section{Acknowledgements}

The work was supported by the interdisciplinary research group KoSar (Kompetenznetz Sarkome, DKH 107153, DKH 109742) with a grant from the Deutsche Krebshilfe (German Cancer Aid). We thank the Tissue Bank of the National Center for Tumor Diseases Heidelberg for providing tissues. The authors thank Katja Böhmer, Jochen Meyer, Marion Moock, Andrea Müller and Kerstin Mühlburger for their excellent technical assistance. We acknowledge the financial support of the Deutsche Forschungsgemeinschaft and Ruprecht-Karls-Universität Heidelberg within the funding programme Open Access Publishing.

\section{Author details}

${ }^{1}$ Department of Neuropathology, Institute of Pathology, University Hospital, Heidelberg, Germany. ${ }^{2}$ German Cancer Consortium (DKTK), CCU Neuropathology, German Cancer Research Center (DKFZ), Heidelberg, Germany. ${ }^{3}$ Department of General Pathology, Institute of Pathology, University Hospital, Im Neuenheimer Feld 224, Heidelberg D-69120, Germany. ${ }^{4}$ Gerhard-Domagk Institute of Pathology, University Hospital, Münster, Germany. ${ }^{5}$ Department of Orthopedics and Traumatology, University Hospital, Heidelberg, Germany. ${ }^{6}$ Department of General, Visceral and Transplantation Surgery, University Hospital, Heidelberg, Germany. ${ }^{7}$ Department of Hematology, Oncology, and Rheumatology, University Hospital, Heidelberg, Germany.

Received: 4 March 2014 Accepted: 8 April 2014 Published: 11 April 2014

\section{References}

1. Fletcher CDM, Bridge JA, Hogendoorn PCW, Mertens F: WHO Classification of Tumours of Soft Tissue and Bone. Lyon: IARC Press; 2013.

2. Goldblum JR, Folpe AL, Weiss SW: General Considerations. In Enzinger and Weiss's Soft Tissue Tumors, Book General Considerations. 6th edition. Edited by Enzinger and Weiss's Soft Tissue Tumors. City: Mosby; 2013:1-10.

3. Stojadinovic A, Yeh A, Brennan MF: Completely resected recurrent soft tissue sarcoma: primary anatomic site governs outcomes. J Am Coll Surg 2002, 194:436-447.

4. Taylor BS, Barretina J, Maki RG, Antonescu CR, Singer S, Ladanyi M: Advances in sarcoma genomics and new therapeutic targets. Nat Rev Cancer 2011, 11:541-557.

5. Renner M, Wolf $T$, Meyer H, Hartmann W, Penzel R, Ulrich A, Lehner B, Hovestadt V, Czwan E, Egerer G, Schmitt T, Alldinger I, Renker EK, Ehemann V, Eils $R$, Wardelmann E, Buttner R, Lichter P, Brors B, Schirmacher $P$, Mechtersheimer $\mathrm{G}$ : Integrative DNA methylation and gene expression analysis in high-grade soft tissue sarcomas. Genome Biol 2013, 14:r137.

6. van de Rijn M, Fletcher JA: Genetics of soft tissue tumors. Annu Rev Pathol 2006, 1:435-466

7. $\mathrm{Xu} \mathrm{L}, \mathrm{Li}$ S, Stohr BA: The role of telomere biology in cancer. Annu Rev Pathol 2013, 8:49-78.

8. Kim NW, Piatyszek MA, Prowse KR, Harley CB, West MD, Ho PL, Coviello GM, Wright WE, Weinrich SL, Shay JW: Specific association of human telomerase activity with immortal cells and cancer. Science 1994, 266:2011-2015.

9. Kyo S, Takakura M, Fujiwara T, Inoue M: Understanding and exploiting hTERT promoter regulation for diagnosis and treatment of human cancers. Cancer Sci 2008, 99:1528-1538.

10. Heidenreich B, Rachakonda PS, Hemminki K, Kumar R: TERT promoter mutations in cancer development. Curr Opin Genet Dev 2014, 24:30-37.
11. Figl A, Rachakonda PS, Fischer C, Sucker A, Gast A, Kadel S, Moll I, Nagore E, Hemminki K, Schadendorf D, Kumar R: TERT promoter mutations in familial and sporadic melanoma. Science 2013, 339:959-961.

12. Huang FW, Hodis E, Xu MJ, Kryukov GV, Chin L, Garraway LA: Highly recurrent TERT promoter mutations in human melanoma. Science 2013, 339:957-959.

13. Arita H, Narita Y, Fukushima S, Tateishi K, Matsushita Y, Yoshida A, Miyakita Y, Ohno M, Collins VP, Kawahara N, Shibui S, Ichimura K: Upregulating mutations in the TERT promoter commonly occur in adult malignant gliomas and are strongly associated with total $1 p 19 q$ loss. Acta Neuropathol 2013, 126:267-276.

14. Griewank KG, Murali R, Schilling B, Scholz S, Sucker A, Song M, Susskind D, Grabellus F, Zimmer L, Hillen U, Steuhl KP, Schadendorf D, Westekemper H, Zeschnigk M: TERT promoter mutations in ocular melanoma distinguish between conjunctival and uveal tumours. Br J Cancer 2013, 109:497-501.

15. Griewank KG, Schilling B, Murali R, Bielefeld N, Schwamborn M, Sucker A, Zimmer L, Hillen U, Schaller J, Brenn T, Schadendorf D, Mentzel T: TERT promoter mutations are frequent in atypical fibroxanthomas and pleomorphic dermal sarcomas. Mod Pathol 2014, 27:502-508.

16. Killela PJ, Reitman Z, Jiao Y, Bettegowda C, Agrawal N, Diaz LA Jr, Friedman AH, Friedman H, Gallia GL, Giovanella BC, Grollman AP, He TC, He Y, Hruban RH, Jallo Gl, Mandahl N, Meeker AK, Mertens F, Netto GJ, Rasheed BA, Riggins GJ, Rosenquist TA, Schiffman M, Shih le M, Theodorescu D, Torbenson MS, Velculescu VE, Wang TL, Wentzensen N, Wood LD, et al: TERT promoter mutations occur frequently in gliomas and a subset of tumors derived from cells with low rates of self-renewal. Proc Natl Acad Sci U S A 2013, 110:6021-6026.

17. Koelsche C, Sahm F, Capper D, Reuss D, Sturm D, Jones DT, Kool M, Northcott PA, Wiestler B, Bohmer K, Meyer J, Mawrin C, Hartmann C, Mittelbronn M, Platten M, Brokinkel B, Seiz M, Herold-Mende C, Unterberg A, Schittenhelm J, Weller M, Pfister S, Wick W, Korshunov A, von Deimling A: Distribution of TERT promoter mutations in pediatric and adult tumors of the nervous system. Acta Neuropathol 2013, 126:907-915.

18. Landa I, Ganly I, Chan TA, Mitsutake N, Matsuse M, Ibrahimpasic T, Ghossein RA Fagin JA: Frequent somatic TERT promoter mutations in thyroid cancer: higher prevalence in advanced forms of the disease. J Clin Endocrinol Metab 2013, 98:E1562-1566.

19. Liu X, Bishop J, Shan Y, Pai S, Liu D, Murugan AK, Sun H, El-Naggar AK, Xing M: Highly prevalent TERT promoter mutations in aggressive thyroid cancers. Endocr Relat Cancer 2013, 20:603-610.

20. Liu X, Wu G, Shan Y, Hartmann C, von Deimling A, Xing M: Highly prevalent TERT promoter mutations in bladder cancer and glioblastoma. Cell Cycle 2013, 12:1637-1638.

21. Nault JC, Mallet M, Pilati C, Calderaro J, Bioulac-Sage P, Laurent C, Laurent A, Cherqui D, Balabaud C, Zucman Rossi J: High frequency of telomerase reverse-transcriptase promoter somatic mutations in hepatocellular carcinoma and preneoplastic lesions. Nat Commun 2013, 4:2218.

22. Nonoguchi N, Ohta T, Oh JE, Kim YH, Kleihues P, Ohgaki H: TERT promoter mutations in primary and secondary glioblastomas. Acta Neuropathol 2013, 126:931-937.

23. Remke M, Ramaswamy V, Peacock J, Shih DJ, Koelsche C, Northcott PA, Hill N, Cavalli FM, Kool M, Wang X, Mack SC, Barszczyk M, Morrissy AS, Wu X, Agnihotri S, Luu B, Jones DT, Garzia L, Dubuc AM, Zhukova N, Vanner R, Kros JM, French PJ, Van Meir EG, Vibhakar R, Zitterbart K, Chan JA, Bognar L, Klekner A, Lach $B$, et al: TERT promoter mutations are highly recurrent in $\mathrm{SHH}$ subgroup medulloblastoma. Acta Neuropathol 2013, 126:917-929.

24. Scott GA, Laughlin TS, Rothberg PG: Mutations of the TERT promoter are common in basal cell carcinoma and squamous cell carcinoma. Mod Pathol 2014, 27:516-523.

25. Vinagre J, Almeida A, Populo H, Batista R, Lyra J, Pinto V, Coelho R, Celestino R, Prazeres H, Lima L, Melo M, da Rocha AG, Preto A, Castro P, Castro L, Pardal F, Lopes JM, Santos LL, Reis RM, Cameselle-Teijeiro J, Sobrinho-Simoes M, Lima J, Maximo $V$, Soares P: Frequency of TERT promoter mutations in human cancers. Nat Commun 2013, 4:2185.

26. Goutagny S, Nault JC, Mallet M, Henin D, Rossi JZ, Kalamarides M: High incidence of activating TERT promoter mutations in meningiomas undergoing malignant progression. Brain Pathol 2014, 24:184-189.

27. Schneider-Stock R, Jaeger V, Rys J, Epplen JT, Roessner A: High telomerase activity and high HTRT mRNA expression differentiate pure myxoid and myxoid/round-cell liposarcomas. Int J Cancer 2000, 89:63-68. 
28. Costa A, Daidone MG, Daprai L, Villa R, Cantu S, Pilotti S, Mariani L, Gronchi A, Henson JD, Reddel RR, Zaffaroni N: Telomere maintenance mechanisms in liposarcomas: association with histologic subtypes and disease progression. Cancer Res 2006, 66:8918-8924

29. Matsuo T, Shimose S, Kubo T, Fujimori J, Yasunaga Y, Sugita T, Ochi M: Correlation between p38 mitogen-activated protein kinase and human telomerase reverse transcriptase in sarcomas. J Exp Clin Cancer Res 2012, 31:5.

30. Schneider-Stock R, Boltze C, Jager V, Epplen J, Landt O, Peters B, Rys J, Roessner A: Elevated telomerase activity, c-MYC-, and hTERT mRNA expression: association with tumour progression in malignant lipomatous tumours. J Pathol 2003, 199:517-525.

31. Yan P, Benhattar J, Coindre JM, Guillou L: Telomerase activity and hTERT mRNA expression can be heterogeneous and does not correlate with telomere length in soft tissue sarcomas. Int J Cancer 2002, 98:851-856.

32. Ulaner GA, Hu JF, Vu TH, Giudice LC, Hoffman AR: Telomerase activity in human development is regulated by human telomerase reverse transcriptase (hTERT) transcription and by alternate splicing of hTERT transcripts. Cancer Res 1998, 58:4168-4172.

33. Zhu S, Rousseau P, Lauzon C, Gandin V, Topisirovic I, Autexier C: Inactive C-terminal telomerase reverse transcriptase insertion splicing variants are dominant-negative inhibitors of telomerase. Biochimie 2014. doi: 10.1016/j.biochi.2013.12.023.

34. Cifuentes-Rojas C, Shippen DE: Telomerase regulation. Mutat Res 2012, 730:20-27.

35. Heaphy CM, de Wilde RF, Jiao Y, Klein AP, Edil BH, Shi C, Bettegowda C, Rodriguez FJ, Eberhart CG, Hebbar S, Offerhaus GJ, McLendon R, Rasheed BA, He Y, Yan H, Bigner DD, Oba-Shinjo SM, Marie SK, Riggins GJ, Kinzler KW, Vogelstein B, Hruban RH, Maitra A, Papadopoulos N, Meeker AK: Altered telomeres in tumors with ATRX and DAXX mutations. Science 2011, 333:425

36. Henson JD, Reddel RR: Assaying and investigating alternative lengthening of telomeres activity in human cells and cancers. FEBS Lett 2010, 584:3800-3811.

37. Cairney CJ, Hoare SF, Daidone MG, Zaffaroni N, Keith WN: High level of telomerase RNA gene expression is associated with chromatin modification, the ALT phenotype and poor prognosis in liposarcoma. Br J Cancer 2008, 98:1467-1474.

38. Venturini L, Motta R, Gronchi A, Daidone M, Zaffaroni N: Prognostic relevance of ALT-associated markers in liposarcoma: a comparative analysis. BMC Cancer 2010, 10:254.

39. Henson JD, Hannay JA, McCarthy SW, Royds JA, Yeager TR, Robinson RA, Wharton SB, Jellinek DA, Arbuckle SM, Yoo J, Robinson BG, Learoyd DL, Stalley PD, Bonar SF, Yu D, Pollock RE, Reddel RR: A robust assay for alternative lengthening of telomeres in tumors shows the significance of alternative lengthening of telomeres in sarcomas and astrocytomas. Clin Cancer Res 2005, 11:217-225.

40. Johnson JE, Gettings EJ, Schwalm J, Pei J, Testa JR, Litwin S, von Mehren M, Broccoli D: Whole-genome profiling in liposarcomas reveals genetic alterations common to specific telomere maintenance mechanisms. Cancer Res 2007, 67:9221-9228.

41. Montgomery E, Argani P, Hicks JL, DeMarzo AM, Meeker AK: Telomere lengths of translocation-associated and nontranslocation-associated sarcomas differ dramatically. Am J Pathol 2004, 164:1523-1529.

42. Dei Tos AP: Liposarcomas: diagnostic pitfalls and new insights. Histopathology 2014, 64:38-52.

43. Fritz B, Schubert F, Wrobel G, Schwaenen C, Wessendorf S, Nessling M, Korz C, Rieker RJ, Montgomery K, Kucherlapati R, Mechtersheimer G, Eils $R$, Joos $S$, Lichter P: Microarray-based copy number and expression profiling in dedifferentiated and pleomorphic liposarcoma. Cancer Res 2002, 62:2993-2998.

44. Pilotti S, Della Torre G, Lavarino C, Sozzi G, Minoletti F, Vergani B, Azzarelli A, Rilke F, Pierotti MA: Molecular abnormalities in liposarcoma: role of MDM2 and CDK4-containing amplicons at 12q13-22. J Pathol 1998, 185:188-190.

45. Rieker RJ, Joos S, Bartsch C, Willeke F, Schwarzbach M, Otano-Joos M, OhI S, Hogel J, Lehnert T, Lichter P, Otto HF, Mechtersheimer G: Distinct chromosomal imbalances in pleomorphic and in high-grade dedifferentiated liposarcomas. Int J Cancer 2002, 99:68-73.

46. Dalal KM, Kattan MW, Antonescu CR, Brennan MF, Singer S: Subtype specific prognostic nomogram for patients with primary liposarcoma of the retroperitoneum, extremity, or trunk. Ann Surg 2006, 244:381-391.
47. Hakin-Smith V, Jellinek DA, Levy D, Carroll T, Teo M, Timperley WR, McKay MJ, Reddel RR, Royds JA: Alternative lengthening of telomeres and survival in patients with glioblastoma multiforme. Lancet 2003, 361:836-838.

48. Wiestler B, Capper D, Holland-Letz T, Korshunov A, von Deimling A, Pfister SM, Platten M, Weller M, Wick W: ATRX loss refines the classification of anaplastic gliomas and identifies a subgroup of IDH mutant astrocytic tumors with better prognosis. Acta Neuropathol 2013, 126:443-451.

49. Schweizer L, Koelsche C, Sahm F, Piro RM, Capper D, Reuss DE, Pusch S, Habel A, Meyer J, Gock T, Jones DT, Mawrin C, Schittenhelm J, Becker A, Heim S, Simon M, Herold-Mende C, Mechtersheimer G, Paulus W, Konig R, Wiestler OD, Pfister SM, von Deimling A: Meningeal hemangiopericytoma and solitary fibrous tumors carry the NAB2-STAT6 fusion and can be diagnosed by nuclear expression of STAT6 protein. Acta Neuropathol 2013, 125:651-658

50. Mantripragada KK, Caley M, Stephens P, Jones CJ, Kluwe L, Guha A Mautner $\mathrm{V}$, Upadhyaya M: Telomerase activity is a biomarker for high grade malignant peripheral nerve sheath tumors in neurofibromatosis type 1 individuals. Genes Chromosomes Cancer 2008, 47:238-246.

51. Rodriguez FJ, Folpe AL, Giannini C, Perry A: Pathology of peripheral nerve sheath tumors: diagnostic overview and update on selected diagnostic problems. Acta Neuropathol 2012, 123:295-319.

52. Venturini L, Daidone MG, Motta R, Cimino-Reale G, Hoare SF, Gronchi A, Folini M, Keith WN, Zaffaroni N: Telomere maintenance mechanisms in malignant peripheral nerve sheath tumors: expression and prognostic relevance. Neuro Oncol 2012, 14:736-744.

53. Sangiorgi L, Gobbi GA, Lucarelli E, Sartorio SM, Mordenti M, Ghedini I, Maini V, Scrimieri F, Reggiani M, Bertoja AZ, Benassi MS, Picci P: Presence of telomerase activity in different musculoskeletal tumor histotypes and correlation with aggressiveness. Int J Cancer 2001, 95:156-161.

doi:10.1186/1756-9966-33-33

Cite this article as: Koelsche et al:: TERT promoter hotspot mutations are recurrent in myxoid liposarcomas but rare in other soft tissue sarcoma entities. Journal of Experimental \& Clinical Cancer Research 2014 33:33.

\section{Submit your next manuscript to BioMed Central and take full advantage of:}

- Convenient online submission

- Thorough peer review

- No space constraints or color figure charges

- Immediate publication on acceptance

- Inclusion in PubMed, CAS, Scopus and Google Scholar

- Research which is freely available for redistribution

Submit your manuscript at www.biomedcentral.com/submit
C) Biomed Central 